\title{
Vessel-Specific Regulation of Angiotensin II Receptor Subtypes During Ovine Development
}

\author{
BLAIR E. COX, XIAO-TIE LIU, STEVEN J. FLUHARTY, AND CHARLES R. ROSENFELD \\ Department of Pediatrics [B.E.C., X.-t.L., C.R.R.], Division of Neonatal-Perinatal Medicine, The \\ University of Texas Southwestern Medical Center at Dallas, Dallas, TX 75390; Departments of Animal \\ Biology and Pharmacology [S.J.F.], School of Veterinary Medicine, and the Institute of Neurological \\ Sciences, University of Pennsylvania, Philadelphia, PA 19104
}

\begin{abstract}
Umbilical and systemic responses to angiotensin II differ in term fetal sheep, and peripheral vascular responses are attenuated or absent before and after birth. These observations may reflect developmental differences in angiotensin II receptor (AT) subtypes in vascular smooth muscle (VSM). Studies of AT subtype ontogeny and regulation are generally limited to the aorta, which may not be extrapolated to other arteries, and neither is completely described during ovine development. We therefore characterized VSM AT subtype expression and regulation throughout an extended period of development in umbilical and carotid artery and aorta from fetal (85-146 d gestation), postnatal (5-23 d), and adult sheep, measuring $\mathrm{AT}_{1}$ and $\mathrm{AT}_{2}$ mRNA and protein and performing immunohistochemistry. Parallel increases in umbilical $\mathrm{AT}_{1}$ mRNA and protein began early in gestation and continued to term, and although $\mathrm{AT}_{2}$ mRNA was unchanged, protein levels decreased $>90 \%$ at term. Fetal carotid $\mathrm{AT}_{1}$ mRNA was $<40 \%$ of adult values and unchanged before birth; however, $\mathrm{AT}_{1}$ protein rose $>2$-fold at term. After birth, $\mathrm{AT}_{1}$ mRNA increased to $85 \%$ of adult values and was associated with another
\end{abstract}

ABSTRACT

2-fold rise in protein. In contrast, carotid $\mathrm{AT}_{2}$ mRNA and protein fell in parallel throughout development and were barely detectable in the newborn and the adult. Immunostaining was consistent with observations in both arteries. A third pattern occurred in aortic VSM. The ontogeny of AT subtype expression and regulation is vessel specific, with changes in umbilical VSM beginning very early in development. Although the mechanisms that regulate mRNA and protein expression are unclear, these changes parallel differences in VSM maturation and function and local blood flow. (Pediatr Res 57: 124-132, 2005)

$\quad$ Abbreviations
Ang II, angiotensin II
AT, angiotensin II receptor
GAPDH, glyceraldehyde-3-phosphate dehydrogenase
MDH, malate dehydrogenase
RAS, renin-angiotensin system
VSM, vascular smooth muscle

The renin-angiotensin system (RAS) is expressed early in gestation and considered an important modulator of cardiovascular development, adaptation, and blood pressure control before and after birth (1-4). In fetal and neonatal sheep, hemorrhage and hypovolemia increase circulating angiotensin II (Ang II) (5-7). Although inhibition of Ang II receptors (AT) or converting enzyme accentuates hypovolemic episodes $(3,7)$, their effects on basal arterial pressure are inconsistent $(8,9)$. AT blockade also modifies the baroreflex and reflex control of renal sympathetic nerve activity after birth $(10,11)$. Recent

Received July 31, 2003; accepted July 22, 2004.

Correspondence: Blair E. Cox, M.D., Department of Pediatrics, The University of Texas Southwestern Medical Center, 5323 Harry Hines Boulevard, Dallas, TX 75390; e-mail: blair.cox@utsouthwestern.edu

This work was supported in part by National Institutes of Health Grant HD08783 and the MacGregor Professorship in Pediatrics.

The data in this article were presented in part at the 48th Annual Meeting of the Society for Gynecologic Investigation; Toronto, Ontario, Canada; March 2001.

DOI: 10.1203/01.PDR.0000148067.07899.B9 evidence suggests the RAS also contributes to the differentiation, maturation, and/or growth of vascular smooth muscle (VSM) (12-15). Thus, prevailing evidence suggests the RAS contributes to the regulation of vascular function, maturation, and growth during development.

The effects of the RAS are mediated primarily by Ang II activation of ATs, which belong to the superfamily of seven transmembrane receptors $(12,16,17)$. They are present in mammalian fetal and adult VSM and demonstrate similar binding characteristics during development and in the adult (18-20). In fetal sheep, AT binding density and affinity in aorta and placental arteries are unchanged in the last third of gestation and resemble adult AT (18). At least two AT subtypes have been identified and characterized $(12,16,17) . \mathrm{AT}_{1}$ is derived from a gene on chromosome 3 , is the predominant receptor in nearly all adult tissues, including VSM, and is responsible for the majority of biologic functions of Ang II via G-protein coupling and calcium-dependent mechanisms, including smooth muscle contraction, cell growth, and fluid and electro- 
lyte regulation $(16,17,21)$. $\mathrm{AT}_{1}$ mRNA is present in aorta of fetal rats and mice throughout development $(14,21,22)$. $\mathrm{AT}_{2}$ is the product of a separate gene on the $\mathrm{X}$ chromosome, has $<40 \%$ amino acid sequence homology with $\mathrm{AT}_{1}(15-17)$, and is highly expressed in fetal and newborn rats $(12,13,15,21)$. It also is present in select adult tissues, including myometrium $(12,23,24)$, adrenal gland $(12,17)$, kidney $(12,15,17)$, uterine artery $(24,25)$, and cerebral vasculature $(12,15)$. It does not mediate smooth muscle contractions, and its function and mechanism(s) of activation, which may be cell specific, are less clear than those of $\mathrm{AT}_{1}(12,13,15-17)$. In fetal mice, $\mathrm{AT}_{2}$ mRNA and protein are not observed in VSM until E14-E15, and expression is undetectable soon after birth $(14,22,26,27)$. However, studies of the ontogeny of AT subtype expression in VSM have been limited primarily to the aorta and changes in subtype mRNA. Thus, it is unclear whether this pattern can be extrapolated to other vascular beds, especially those involved in regulating blood pressure and ensuring fetal growth or well-being, e.g. umbilical and carotid arteries.

Fetal and newborn sheep are an excellent in vivo model for studies of cardiovascular development and function and have provided much of our understanding of the physiology of the RAS during development. Because fetal sheep are larger and prenatal development occurs over $145 \mathrm{~d}$ versus $21 \mathrm{~d}$ in the rat and mouse, it is possible to delineate transitions in vascular biology and physiology before and after birth. However, studies of AT subtype expression and regulation in VSM do not extend across development $(18-20,28)$. Thus we sought to determine 1) whether ovine AT subtype expression in VSM is developmentally regulated and tissue specific, 2) whether differences exist in AT subtype expression in umbilicoplacental and systemic vasculature during development, and 3) whether subtype regulation differs at a molecular level. We studied the umbilical artery, because it regulates fetal oxygen and nutrient delivery and is more sensitive to Ang II at term than the systemic vasculature $(9,29,30)$, and the carotid artery, because it contributes to cerebral blood flow regulation (31). We also examined aortic VSM as it has been extensively studied in the rat and mouse.

\section{METHODS}

Tissue preparation. Samples of umbilical and carotid artery and abdominal aorta were collected from 20 fetal sheep between 85 and $146 \mathrm{~d}$ gestation (term $\sim 145 \mathrm{~d}$ ); samples of carotid artery and aorta were also obtained from 6 postnatal (5-23 d) and 3 adult sheep of mixed Western breed. These vessels were studied because we $(9,19,29)$ previously identified differences in VSM maturation and function as well as AT subtype in umbilical and peripheral arteries at term. Animals were killed with i.v. pentobarbital sodium (120 $\mathrm{mg} / \mathrm{kg}$ ), which when given to pregnant ewes simultaneously kills the fetus. In pregnant animals, the fetus was rapidly delivered, dried, weighed, and measured to confirm gestational age. A 6- to 8-cm segment of umbilical cord was obtained, and both umbilical arteries were dissected, placed into chilled physiologic based saline, and maintained on ice as previously described $(29,32)$. Residual blood was expressed, and Wharton's jelly and adventitia were removed using blunt and sharp dissection. A subset of arteries was opened, and the endothelium was removed with a cotton-tipped applicator, which was confirmed histologically in random samples as previously reported $(33,34)$. The remaining medial VSM was frozen in liquid nitrogen and stored at $-80^{\circ} \mathrm{C}$. Samples of carotid artery and aorta were similarly prepared. These studies were approved by the Institutional Animal Care and Research Advisory Committee.

Reverse transcription-PCR. A semiquantitative reverse transcription-PCR (RT-PCR) assay was used to determine $\mathrm{AT}_{1}$ and $\mathrm{AT}_{2}$ mRNA in VSM as previously reported (34). Briefly, arterial segments were removed from $-80^{\circ} \mathrm{C}$, and total cellular RNA was extracted from the denuded VSM from each artery by a single extraction with chloroform, precipitated with isopropanol, washed with $80 \%$ ethanol, and resuspended in $50 \mu \mathrm{L}$ of $0.1 \%$ DEPC water. The concentration and the purity were measured at $260 \mathrm{~nm}$ OD. RT was performed with $2 \mu \mathrm{g}$ of total RNA in $50 \mu \mathrm{L}$ of reaction solution that contained $200 \mathrm{U}$ of Moloney murine leukemia virus reverse transcriptase (GIBCO/BRL, Life Technologies, Inc., Gaithersburg, MD), $1 \mu \mathrm{L}$ of $0.5 \mu \mathrm{g} / \mu \mathrm{L}$ of oligo dT (16), $10 \mu \mathrm{L}$ of $5 \times$ first-strand buffer [ $250 \mathrm{mM}$ of Tris-Cl (pH 8.3), $375 \mathrm{mM}$ of $\mathrm{KCl}$, and $15 \mathrm{mM}$ of $\mathrm{MgCl}_{2}$ ], $5 \mu \mathrm{L}$ of $0.1 \mathrm{M}$ of DTT, $4 \mu \mathrm{L}$ of $10 \mathrm{mM}$ of dNTPs (2.5 mM each of dATP, dCTP, dGTP, and dTTP), and 0.1\% DEPC water to adjust volume. The reaction was incubated at room temperature for $10 \mathrm{~min}$, at $37^{\circ} \mathrm{C}$ for $1 \mathrm{~h}$, and terminated at $95^{\circ} \mathrm{C}$ for $5 \mathrm{~min}$. The RNA loaded, $2 \mu \mathrm{g}$, was on the linear portion of a loading curve for each species, which extended between 0 and $4 \mu \mathrm{g}$ (data not shown).

PCR was performed on $1.0 \mu \mathrm{L}$ of RT product with specific primers designed from nucleotide sequences for $\mathrm{AT}_{1}$ and $\mathrm{AT}_{2}$ receptors identified from existing sequences in the sheep (synthesized by Life Technologies). Malate dehydrogenase (MDH) was chosen as the reference gene because glyceraldehyde-3-phosphate dehydrogenase (GAPDH) is reported to vary during ovine development (35). The PCR primers were as follows: $\mathrm{AT}_{1}$ receptor, 5'-CTTTGTGGTGGGGCTATTTGG-3' (forward) and 5'-AAAAGTGAATATCTGGTGGGGA-3' (reverse), 671 bp; $\mathrm{AT}_{2}$ receptor, 5'-CCTGTTCTCTATTACATTAT-3' (forward) and 5'GCTATAACTTCACAGCTATTA-3' (reverse), 741 bp; MDH, 5'-AAATCTTCGGGGTGACAACC-3' (forward) and 5'-TCCCAGCAGCAACGGTGT-3' (reverse), $369 \mathrm{bp}$. After a 4-min initial denaturation at $94^{\circ} \mathrm{C}$, amplification conditions were $\mathrm{AT}_{1}$ at $94^{\circ} \mathrm{C}$ for $45 \mathrm{~s}, 56^{\circ} \mathrm{C}$ for $60 \mathrm{~s}$, and $72^{\circ} \mathrm{C}$ for $60 \mathrm{~s}$ for 30 sequential cycles; $\mathrm{AT}_{2}$ at $94^{\circ} \mathrm{C}$ for $40 \mathrm{~s}, 50^{\circ} \mathrm{C}$ for $60 \mathrm{~s}$, and $72^{\circ} \mathrm{C}$ for $60 \mathrm{~s}$ for 33 sequential cycles; and $\mathrm{MDH}$ at $95^{\circ} \mathrm{C}$ for $45 \mathrm{~s}, 59^{\circ} \mathrm{C}$ for $60 \mathrm{~s}$, and $72^{\circ} \mathrm{C}$ for $60 \mathrm{~s}$ for 33 sequential cycles followed by $72^{\circ} \mathrm{C}$ final extension for $7 \mathrm{~min}$. The cycles noted for DNA amplification were on the linear portion of the assay curve for each artery and were run at optimum temperature.

PCR products were size-fractionated by applying $10 \mu \mathrm{L}$ on $1.5 \%$ agarose gels that contained $25 \mu \mathrm{g} / \mu \mathrm{L}$ of ethidium bromide and visualized under UV light. Optical densities of DNA bands were scanned and quantified using Scion Image software (Scion Corp., Frederick, MD). The accuracy of amplified sequences was verified by purifying the PCR products from agarose gels and sequencing them (UT Southwestern Medical Center DNA Sequencing Facility Core). When values were compared across development, the targeted PCR products were always run on the same gel.

Western immunoblots. SDS homogenates were prepared from 15- to 20-mg samples of frozen denuded samples of umbilical and carotid artery using methods previously reported (29). The homogenate was divided into two aliquots; one was subjected to centrifugation at $10,000 \times g$ for $2 \mathrm{~min}$ and the supernatant was removed, providing samples of total and soluble or cellular protein, respectively. For selected samples, we isolated the plasma membranes from umbilical and carotid arteries soon after tissue collection as previously reported (19) and stored samples at $-80^{\circ} \mathrm{C}$ until assayed. Protein contents were measured by BCA reagent (Pierce, Rockford, IL). After determining the distribution of receptor protein in preliminary studies (see "Results"), we used 2 or $10 \mu \mathrm{g}$ of soluble protein to assess AT subtype expression in umbilical and carotid VSM, subjecting samples to electrophoresis in $7.5 \%$ polyacrylamide gels. Proteins were electrophoretically transferred to nitrocellulose paper (Amersham Pharmacia Biotech Inc., Piscataway, NJ) at $100 \mathrm{mV}$ for $1 \mathrm{~h}$. Blots were blocked for $1 \mathrm{~h}$ in buffer that contained powdered milk (5\% wt/vol) and incubated overnight at $4{ }^{\circ} \mathrm{C}$ with blocking buffer that contained specific antisera against $\mathrm{AT}_{1}(1: 1500)$ and $\mathrm{AT}_{2}(1: 3000)$ receptors. We used two $\mathrm{AT}_{1}$ antisera previously used for detecting ovine $\mathrm{AT}_{1}$ receptors (4): N-10 (anti-rabbit from rat sequence N-terminal; Santa Cruz Biotechnology, Inc., Santa Cruz, CA) and C306 (human sequence a.a. 306-359; Santa Cruz Biotechnology). The $\mathrm{AT}_{2}$ antisera were raised in rabbits in the laboratories of Dr. Steven J. Fluharty and have been extensively validated (36,37). These antisera do not cross-react between the $\mathrm{AT}_{1}$ and $\mathrm{AT}_{2}$ receptors (data not shown). Antisera were diluted in $0.05 \%$ Tween-20-Tris-buffered saline (TTBS). The nitrocellulose paper was then washed and incubated for $1 \mathrm{~h}$ at room temperature with donkey anti-rabbit 
IgG conjugated with affinity-purified horseradish peroxidase diluted at 1:5000 with TTBS. Receptor proteins were visualized by enhanced chemiluminescence (Amersham). Blots were kept in the developing solution for $1 \mathrm{~min}$ exposed on film for $\sim 1 \mathrm{~min}$, and then developed. Densitometry was performed, and the values for each band were averaged and expressed as arbitrary units.

Immunohistochemistry. At the time of tissue collection, intact segments of umbilical and carotid artery were washed in PBS, fixed in $4 \%$ paraformaldehyde for $6 \mathrm{~h}$ at room temperature, and embedded in paraffin as previously reported $(33,34)$. Fixed, paraffin-embedded tissues were sectioned at $5-\mu$ intervals, mounted on super frost-plus slides, deparaffinized, placed in $100 \mathrm{mM}$ of glycine buffer $(\mathrm{pH} 3.55)$, and microwaved for antigen retrieval. Tissues were hydrated; incubated with avidin-biotin blocking agent for $30 \mathrm{~min}$ (Vector Labs, Burlington, CA); and incubated overnight at room temperature with 1:200 $\mathrm{AT}_{1}$ polyclonal antibody (N-10; Santa Cruz Biotech), 1:300 $\mathrm{AT}_{2}$ polyclonal antibody, or nonimmune rabbit serum as a negative control. After endogenous peroxidases were quenched with $3 \% \mathrm{H}_{2} \mathrm{O}_{2}$ in $90 \%$ methanol for $30 \mathrm{~min}$, immunostaining was detected with standard streptavidin-biotin-horseradish peroxidase and hematoxylin counterstaining.

Statistical analyses. Changes across development were analyzed using regression analysis with the $x$ axis as developmental age in days and the $y$ axis as AT subtype mRNA or protein. To determine when in development changes may have occurred in subtype expression, we also divided animals into groups representing fetal $[\leq 100 \mathrm{~d}(n=5), 101-130 \mathrm{~d}(n=8)$, and $131-146 \mathrm{~d}(n=$ $7)$ ], postnatal [birth-1 mo $(n=6)$ ], and adults $(n=3)$ as previously reported (39). Groups were compared using one-way ANOVA for multiple groups. Different letters for groups demonstrate significant differences at $p<0.05$. Data are presented as means \pm SEM.

\section{RESULTS}

Effects of development on VSM MDH mRNA. GAPDH mRNA varies during ovine development, excluding its use as a reference gene (35). We therefore determined in preliminary studies whether MDH mRNA in umbilical, carotid, and aortic VSM was modified during ovine development. There was an age-dependent rise $\left(r^{2}=0.78, n=11, p<0.001\right.$, ANOVA) in umbilical VSM MDH during gestation (Fig. 1), whereas values in fetal and postnatal carotid VSM did not differ $(p>$ 0.2 ; Fig. 1). Rather than search for an unaffected reference gene for umbilical VSM, we chose to reference levels of $\mathrm{AT}_{1}$ and $\mathrm{AT}_{2}$ mRNA to a standard sample obtained at $141 \mathrm{~d}$ as previously reported using immunoblot analysis (29). At this time,

\section{A. RT-PCR}

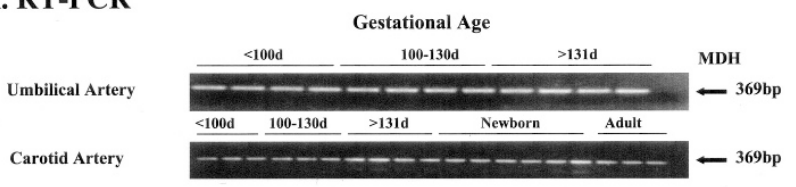

\section{B. Densitometry}
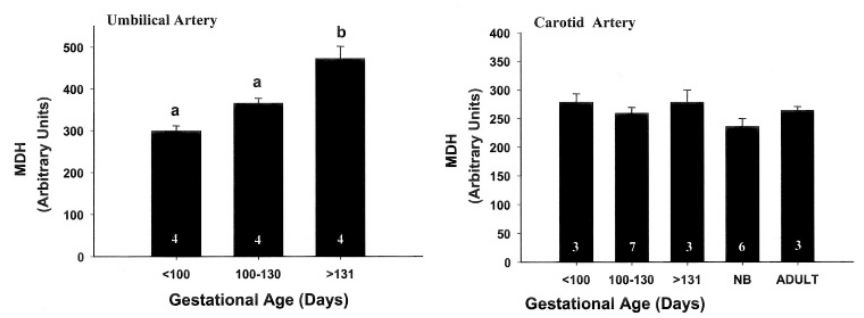

Figure 1. Comparison of MDH mRNA in umbilical and carotid artery smooth muscle during ovine development. (A) Representative RT-PCR for MDH mRNA. (B) Results of densitometric analysis in arbitrary units. Different letters represent significant differences between groups at $p<0.001$ using ANOVA.
$\mathrm{AT}_{1}$ binding density is maximum, whereas $\mathrm{AT}_{2}$ binding is minimal (19). Because carotid VSM MDH was unchanged, we used the AT subtype/MDH mRNA ratio to assess the semiquantitative changes in subtype mRNA in carotid VSM. Aortic VSM MDH mRNA also was unchanged during ovine development ( $p>0.1$; data not shown); thus, the AT/MDH mRNA ratio was also used to assess changes in aortic VSM.

Developmental changes in AT subtype mRNA. Umbilical VSM AT ${ }_{1}$ mRNA rose in an age-dependent manner during the last two thirds of gestation $(p=0.002$, ANOVA), values increasing 1.8-fold between $<100 \mathrm{~d}$ and $100-130 \mathrm{~d}$ gestation and an additional $38 \%$ in the last $2 \mathrm{wk}$ of pregnancy, a total increase of 2.5-fold (Fig. 2). In contrast, umbilical VSM AT 2 mRNA was unchanged throughout gestation $(p>0.1$, ANOVA).

A different pattern of expression of AT subtype mRNA was observed in carotid VSM. Although $\mathrm{AT}_{1}$ receptor mRNA was unchanged during the last two thirds of gestation (Fig. 3), values increased $\sim 2$-fold in the first month after birth and an additional $89 \%$ in the adult $\left(p<0.001\right.$, ANOVA). Carotid $\mathrm{AT}_{2}$ mRNA also differed, falling throughout the last third of gestation $(p<0.001$, ANOVA), levels decreasing $38 \%$ by $100-130$ $\mathrm{d}$ gestation and $71 \%$ in near-term and term fetal sheep. Levels of $\mathrm{AT}_{2}$ mRNA after birth and in the adult were similar and barely detectable, having fallen $>83 \%$ since the middle third of gestation.

Although the umbilical and carotid arteries play integral roles in modifying blood flow to essential tissues, the majority of existing data regarding the developmental expression of AT subtypes in VSM have been derived from the rat and/or mouse aorta and reported as changes in mRNA $(14,16,21,22,26,27)$. Thus, we wished to determine whether the pattern of AT subtype mRNA expression in the ovine aorta resembled that in the rodent and the umbilical and carotid arteries. A third pattern of AT subtype mRNA expression was observed in aortic VSM. As in carotid VSM, levels of aortic $\mathrm{AT}_{1}$ mRNA were unchanged during the last two thirds of gestation $(p>$ 0.2 , ANOVA; Fig. 4); however, they also were unchanged in

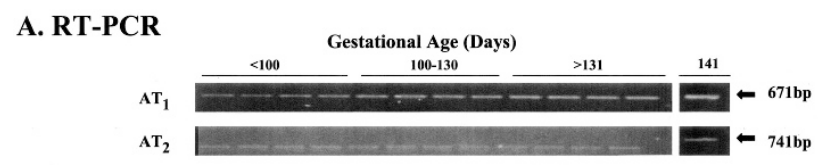

\section{B. Densitometry}
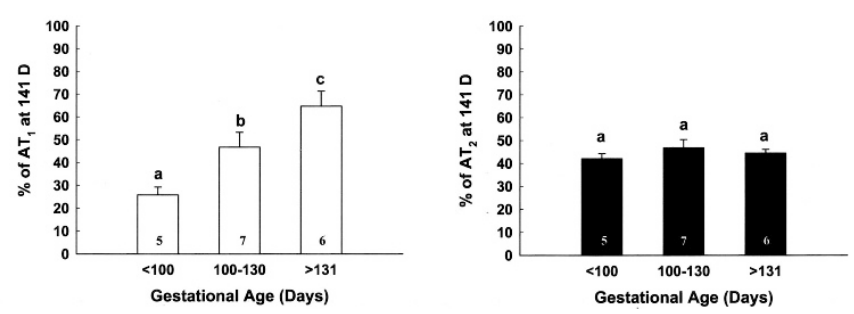

Figure 2. Comparison of $\mathrm{AT}_{1}$ and $\mathrm{AT}_{2}$ receptor mRNA in umbilical artery smooth muscle across ovine gestation. (A) Representative RT-PCR for $\mathrm{AT}_{1}$ and $\mathrm{AT}_{2}$ mRNA. $(B)$ Results of densitometric analyses using the AT:AT ratio at $141 \mathrm{~d}$ gestation. The 141-d reference sample is shown. Different letters represent significant differences between groups at $p=0.002$ using ANOVA. 


\section{A. RT-PCR}

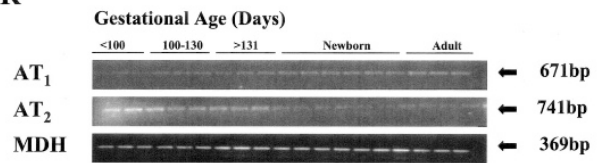

\section{B. Densitometry}
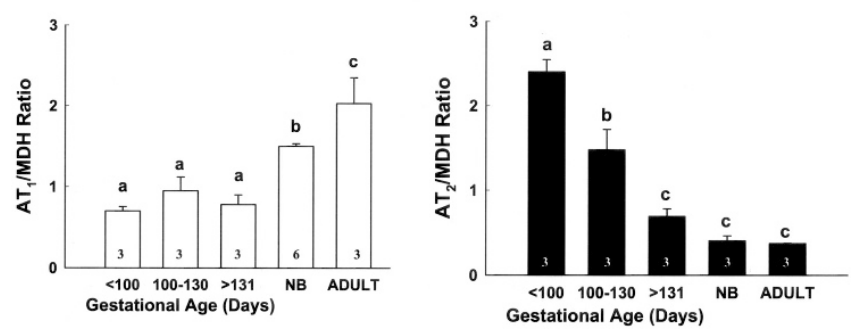

Figure 3. Comparison of $\mathrm{AT}_{1}, \mathrm{AT}_{2}$, and $\mathrm{MDH}$ mRNA in carotid artery smooth muscle during ovine development. (A) Representative RT-PCR for $\mathrm{AT}_{1}, \mathrm{AT}_{2}$, and $\mathrm{MDH}$. (B) Results of densitometric analysis of $\mathrm{AT}_{1}$ and $\mathrm{AT}_{2}$ as the AT:MDH ratio. Different letters represent significant differences between groups at $p<0.001$ using ANOVA.

\section{A. RT-PCR}

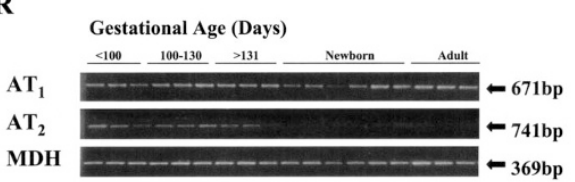

\section{B. Densitometry}
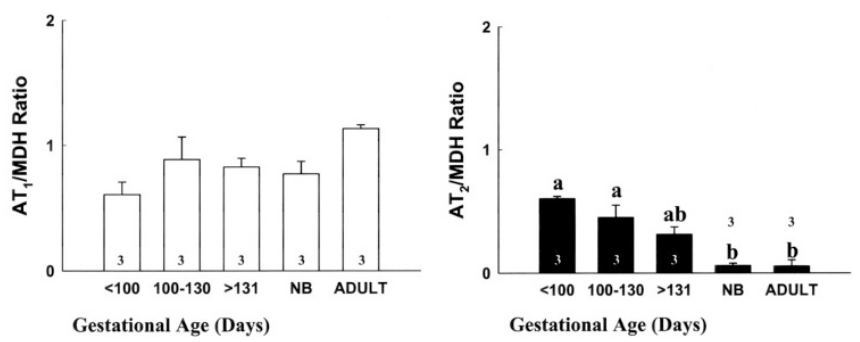

Figure 4. Comparison of $\mathrm{AT}_{1}, \mathrm{AT}_{2}$, and $\mathrm{MDH}$ mRNA in aortic smooth muscle during ovine development. (A) Representative RT-PCR for $\mathrm{AT}_{1}, \mathrm{AT}_{2}$, and MDH mRNA. $(B)$ Results of densitometric analysis of $\mathrm{AT}_{1}$ and $\mathrm{AT}_{2}$ as the AT:MDH ratio. Different letters represent significant differences between groups at $p<0.001$ using ANOVA.

the first postnatal month $\left(r^{2}=0.06, n=15, p=0.4\right.$ and ANOVA, $p>0.2$ ) and in the adult. Aortic VSM AT 2 mRNA seemed to fall progressively throughout development by regression analysis $\left(r^{2}=0.74, n=15, p<0.0001\right)$, but values were unchanged until after birth, at which time $\mathrm{AT}_{2}$ mRNA decreased $>90 \%$ and was barely detectable, resembling values in the adult aorta.

Developmental changes in AT subtype protein. RT-PCR provides important insights into the regulation of gene expression but does not consistently define changes in protein expression or translation. Few investigators studying the ontogeny of AT subtypes have reported simultaneous changes in vascular mRNA and protein. Thus, we used immunoblot analysis to examine the developmental changes in VSM AT subtype protein in umbilical and carotid VSM. In preliminary studies, we first determined which protein fraction of VSM best characterized the ontogeny of AT subtype expression. To accomplish this, we simultaneously measured $\mathrm{AT}_{1}$ protein in preparations of plasma membrane fraction as well as the soluble and total protein fractions from $113 \mathrm{~d}$ gestation umbilical and adult carotid VSM using two antisera (see "Methods"). Three molecular weight species of $\mathrm{AT}_{1}$ protein were detected in both VSM at 102, 67, and $35 \mathrm{kD}$ (Fig. 5); however, there were major differences among the antisera. The C-306 antisera recognized the $102-\mathrm{kD}$ species as the predominant protein in all VSM fractions from both vessels, but values were $>2$-fold greater in the total and soluble protein than in the plasma membrane fraction of both vessels. The $67-\mathrm{kD}$ protein was seen only in the plasma membrane fraction and was $<50 \%$ of values at $102 \mathrm{kD}$, whereas the $35-\mathrm{kD}$ species was minimally present in all fractions. In contrast, antisera N-10 predominantly detected a $67-\mathrm{kD}$ protein species, whereas both the $102-$ and $35-\mathrm{kD}$ species were minimally seen (Fig. 5). Again, the protein was predominantly in the soluble and total protein fractions. The $\mathrm{AT}_{2}$ antisera detected only a $63-\mathrm{kD}$ protein (not shown), consistent with previous reports in the rat and mouse $(36,37)$.

Because the 102- and $67-\mathrm{kD}$ species of the $\mathrm{AT}_{1}$ receptor predominated in umbilical VSM and were primarily in the soluble or cellular protein fractions, we examined the developmental changes in both protein species in umbilical VSM. There was a highly significant, progressive rise $(r \geq 0.88, p \leq$ $0.0004)$ in both species of $\mathrm{AT}_{1}$ protein in umbilical VSM across gestation, levels increasing $>2.5$-fold by term gestation (Fig. 6). Furthermore, this was paralleled by a reciprocal fall in $\mathrm{AT}_{2}$ protein (Fig. 7), resulting in barely detectable levels at term gestation $(r=0.98, p<0.0001)$.

Although we measured AT subtype mRNA in both carotid and aortic VSM, we chose to study AT subtype protein expression in the former because it plays an important role in modulating cerebral blood flow and thus may have physiologic

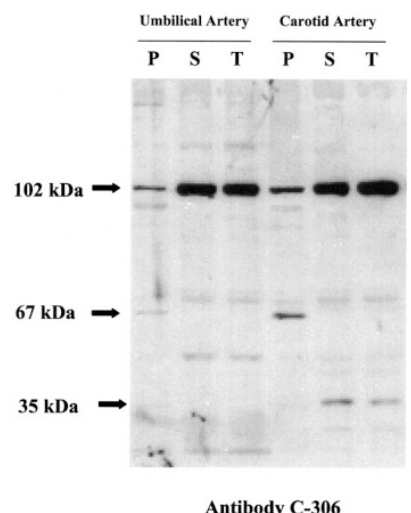

Antibody C-306

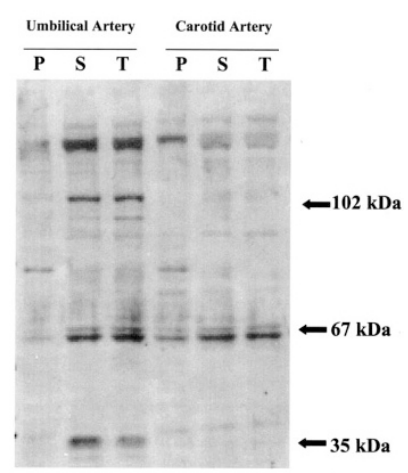

Antibody N-10
Figure 5. Representative immunoblots demonstrating the differences in $\mathrm{AT}_{1}$ receptor species expressed in fractions of plasma membrane $(\mathrm{P})$ and soluble $(\mathrm{S})$ and total $(\mathrm{T})$ protein obtained from umbilical and carotid artery smooth muscle using two commercially available antisera (see "Methods"). Two micrograms of protein was loaded for each lane to detect $\mathrm{AT}_{1}$ protein with C-306 (derived from the human $\mathrm{C}$-terminal sequence). The $102-\mathrm{kD}$ species is the predominant form observed in both arteries, is present in all fractions, and is predominantly in the soluble and total protein fractions. Ten micrograms of protein was loaded for each lane to detect $\mathrm{AT}_{1}$ protein with $\mathrm{N}-10$ (derived from the rat $\mathrm{N}$-terminal sequence). The $67-\mathrm{kD}$ species is the predominant form and also is primarily in the soluble and total protein fractions of both vessels. 
A. Western Analysis

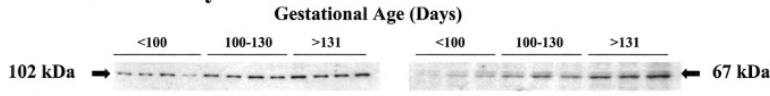

\section{B. Densitometry}
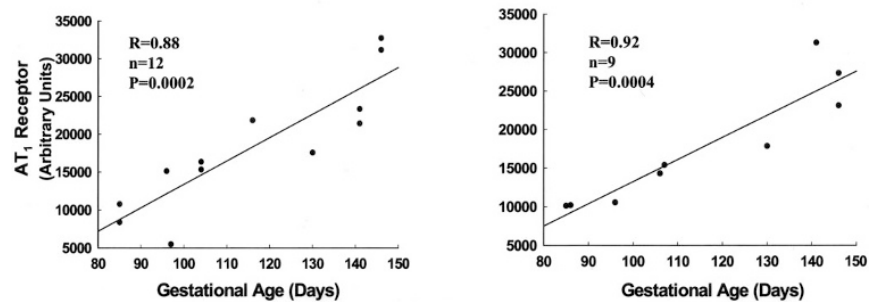

Figure 6. Comparison of changes in $\mathrm{AT}_{1}$ receptor protein expression in umbilical artery smooth muscle across ovine gestation using antisera that detected protein species at 102 and $67 \mathrm{kD}$. The antiserum for the former was derived from the human $\mathrm{AT}_{1} \mathrm{C}$-terminal sequence, whereas the latter was derived from the rat $\mathrm{N}$-terminal sequence. $(A)$ Representative immunoblots demonstrating changes in the $102-$ and $67-\mathrm{kD} \mathrm{AT}_{1}$ proteins. $(B)$ Results of densitometric analysis in arbitrary units. The respective regression equations are shown in the figures.

\section{A. Western Analysis}

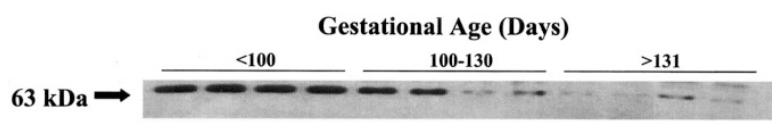

\section{B. Densitometry}

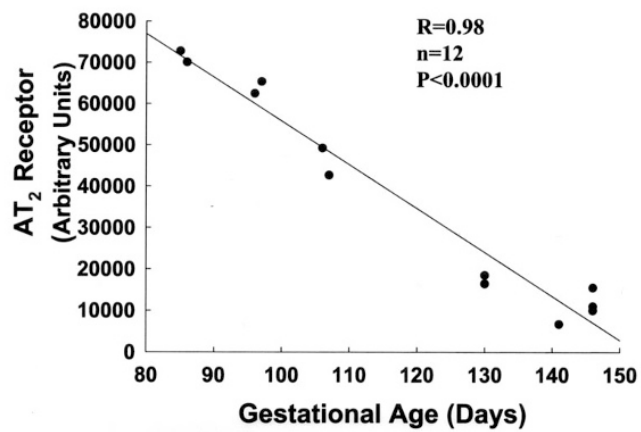

Figure 7. Changes in $\mathrm{AT}_{2}$ receptor protein expression in umbilical artery smooth muscle during ovine gestation using antisera raised in rabbit to detect 63-kD species. (A) Representative immunoblot demonstrating changes in $\mathrm{AT}_{2}$ protein. $(B)$ Results of densitometric analysis in arbitrary units.

implications. Because the developmental pattern of the 102and $67-\mathrm{kD}$ proteins in umbilical VSM was similar and the former was readily detectable with the C-306 antisera using 2 $\mu \mathrm{g}$ of protein versus $10 \mu \mathrm{g}$ with the $\mathrm{N}-10$ antisera, suggesting that it might be the predominant protein species, we measured only the $102-\mathrm{kD}$ protein in carotid VSM. Levels of $\mathrm{AT}_{1}$ protein increased in an age-dependent manner, beginning early in the last third of gestation. Values increased 4.6 -fold by term gestation, 9.4-fold in the first postnatal month, and 14-fold in the adult when compared with levels at $<100 \mathrm{~d}$ gestation $(p<$ 0.001, ANOVA; Fig. 8). The converse was observed in $\mathrm{AT}_{2}$

\section{A. Western Analysis}

Gestational Age (Days)

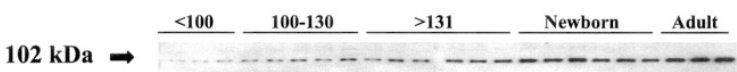

\section{B. Densitometry}

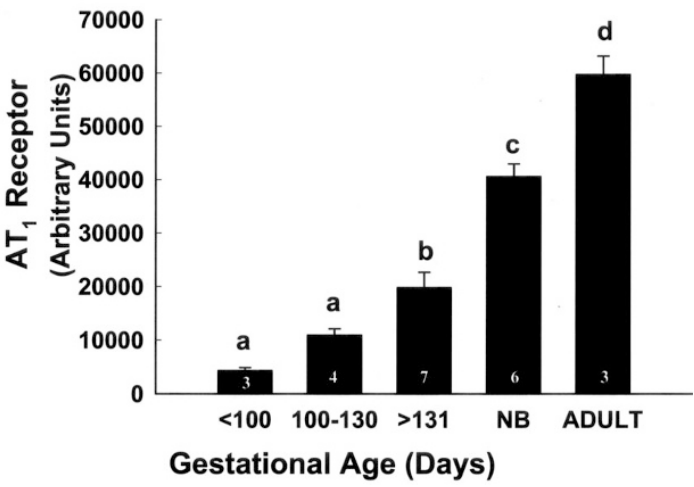

Figure 8. Changes in $\mathrm{AT}_{1}$ receptor protein expression in carotid artery smooth muscle during ovine development using antisera C-306 derived from the human $\mathrm{AT}_{1} \mathrm{C}$-terminal sequence that detects a $102-\mathrm{kD}$ species. $(A)$ Representative immunoblot demonstrating changes in $\mathrm{AT}_{2}$ protein. $(B)$ Results of densitometric analysis in arbitrary units. Different letters represent significant differences between groups at $p<0.001$ by ANOVA.

\section{A. Western Analysis}

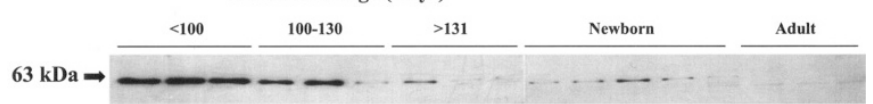

\section{B. Densitometry}

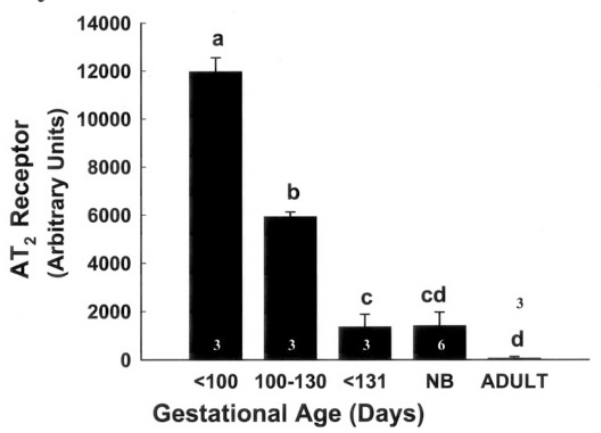

Figure 9. Changes in $\mathrm{AT}_{2}$ receptor protein expression in carotid artery smooth muscle during ovine development. (A) Representative immunoblot. $(B)$ Results of densitometric analysis in arbitrary units. Different letters represent significant differences between groups at $p<0.001$ using ANOVA.

protein (Fig. 9), i.e. levels at $<100 \mathrm{~d}$ gestation were 12 -fold greater than that at term and after birth and $\sim 120$-fold greater than levels in adult carotid VSM, having decreased $99.5 \%$ in the adult ( $r=0.82, n=15, p=0.0002)$.

Immunohistochemistry. Additional samples of intact umbilical and carotid arteries were collected and prepared for immunohistochemistry to assess the sites of AT subtype expression within the arterial wall. Umbilical arteries demonstrated $\mathrm{AT}_{1}$ immunostaining in the media at $95 \mathrm{~d}$ gestation (Fig. 10A and $B$ ), and this was markedly increased throughout the media 

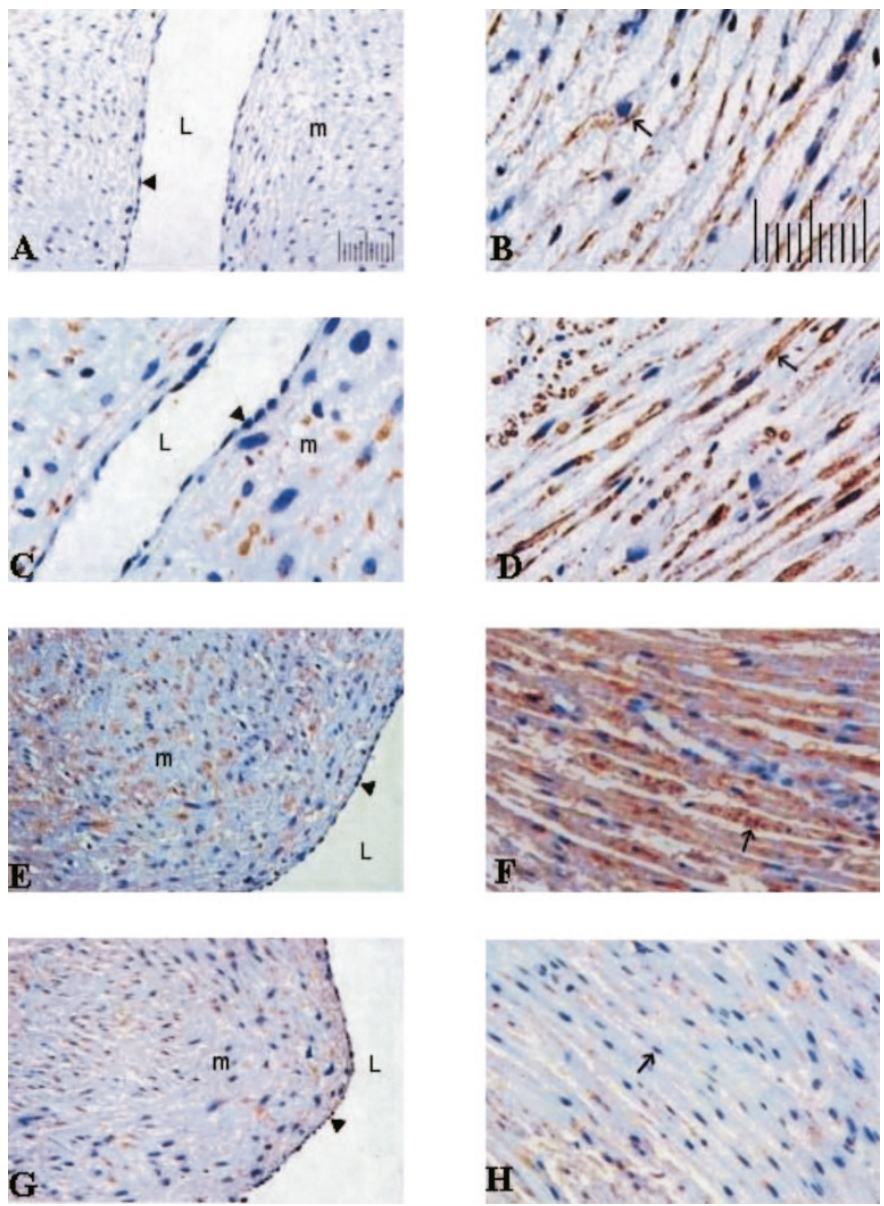

Figure 10. Representative immunohistochemistry of $\mathrm{AT}_{1}$ and $\mathrm{AT}_{2}$ expression in the umbilical artery during ovine development. $\mathrm{AT}_{1}$ immunostaining in the medial smooth muscle is minimal at $95 \mathrm{~d}$ gestation $(A$ and $B)$ and is markedly increased at $130 \mathrm{~d}$ gestation $(C$ and $D$ ); immunostaining is restricted to the media at both ages. The opposite is seen with the $\mathrm{AT}_{2}$ receptor, i.e. there is substantial immunostaining in the media at $95 \mathrm{~d}(E$ and $F)$ that is barely detectable at $130 \mathrm{~d}(G$ and $H)$. The arterial lumen (L) and media (m) as well as endothelial $(\boldsymbol{\nabla})$ and smooth muscle $(\leftarrow)$ cells are identified. Magnification: $\times 20$ in $A, C, E$, and $G ; \times 40$ in $B, D, F$, and $H$.

at $130 \mathrm{~d}$ gestation (Fig. $10 C$ and $D$ ). The opposite pattern was seen with the $\mathrm{AT}_{2}$ subtype; i.e. immunostaining was intense at $95 \mathrm{~d}$ gestation (Fig. $10 E$ and $F$ ) but barely detectable at $130 \mathrm{~d}$ gestation (Fig. $10 G$ and $H$ ). At neither age was there evidence of histologic changes in the umbilical artery in $\mathrm{AT}_{1}$ or $\mathrm{AT}_{2}$ expression in the endothelium. The pattern of carotid artery immunostaining differed from that in the umbilical artery. There was no $\mathrm{AT}_{1}$ immunostaining in the media at $88 \mathrm{~d}$ gestation (Fig. 11D), modest immunostaining at $130 \mathrm{~d}$ (Fig. $11 E$ ), and a marked increase by $7 \mathrm{~d}$ postnatal (Fig. 11F), consistent with immunoblot analysis. This increase in $\mathrm{AT}_{1}$ immunostaining was associated with a reciprocal decrease in the intensity of $\mathrm{AT}_{2}$ immunostaining in the media, resulting in barely detectable levels at $7 \mathrm{~d}$ postnatal (Fig. $11 G-I$ ). As in the umbilical artery, there was no evidence of endothelial immunostaining. Although there were no histologic changes in umbilical artery morphology, there seems to be an increase in the subendothelial cell density in the carotid artery between $88 \mathrm{~d}$ gestation and $7 \mathrm{~d}$ postnatal and in medial thickness (Fig. $11 A-C)$, demonstrating vascular growth.

\section{DISCUSSION}

The role of the RAS in vascular development and blood pressure regulation in the fetus and neonate remains unclear. For Ang II to contribute to vascular tone and blood pressure regulation, functional $\mathrm{AT}_{1}$ receptors must be present in VSM and the cellular mechanisms responsible for VSM contraction must be intact $(16,17,29,38)$. Although vascular AT subtype expression has been extensively described in aorta from the developing rat and mouse $(14,16,21,22,26,27)$, the aorta contributes little to cardiovascular regulation $(29,39)$, and functional data in these species are lacking. Fetal and neonatal sheep permit studies of the RAS in cardiovascular development and function, but descriptions of AT subtype ontogeny are incomplete $(19,20,28)$. We previously reported that $\mathrm{AT}_{2}$ receptor binding predominated in ovine peripheral VSM until $\sim 4 \mathrm{wk}$ postnatal, whereas only umbilical VSM had predominant $\mathrm{AT}_{1}$ binding in the last 2-3 wk of gestation $(9,19)$. Thus, increases in umbilicoplacental resistance seemed to be a major determinate of Ang II-mediated increases in fetal blood pressure at term, whereas changes in peripheral resistance played a minor role in the fetus and neonate $(9,40)$. The RAS may have other effects on VSM development, e.g. growth and maturation $(12,13,15,22)$; thus, it is important to understand vascular AT subtype expression and regulation during ovine development, especially in vascular beds that contribute to fetal well-being and growth. We now report not only that the ontogeny of AT subtype expression is vessel specific but also that there is evidence of differences in transcription and translation. We also provide additional evidence that umbilical VSM AT subtype expression is precocious, mirroring changes in VSM protein and function (29). Furthermore, we believe that these data raise questions regarding the relationship between AT subtype expression and VSM maturation.

Fetal and neonatal development is marked by rapid growth accompanied by an orderly sequence of maturational changes that generally accompany alterations in function and promote fetal-well being and growth. In VSM, cellular differentiation is followed by maturational events that are organ and vessel specific $(29,32,38,39)$. We therefore hypothesized that similar changes might occur in the RAS and, in particular, in VSM AT subtype expression. Not to our surprise, three patterns of AT subtype expression were observed in VSM, but only the umbilical artery demonstrated progressive increases in $\mathrm{AT}_{1}$ mRNA and protein well in advance of birth that were associated with a reciprocal fall in $\mathrm{AT}_{2}$ protein to barely detectable levels at term, although mRNA was unchanged. This pattern of subtype expression is consistent with changes in receptor binding (19). Thus, only umbilical VSM AT subtype expression resembles adult VSM before birth $(16,17,19)$. The early presence of the $\mathrm{AT}_{1}$ parallels the precocious maturation previously seen in VSM protein expression and function (29). This not only supports our thesis that the umbilical artery makes a major contribution to fetal pressor responses to Ang II at term but also suggests that this occurs throughout the last third of gestation. Additional support is provided by Kaiser et al. (9), who reported that inhibition of umbilicoplacental vascular $\mathrm{AT}_{1}$ receptors in term fetal sheep dose-dependently 

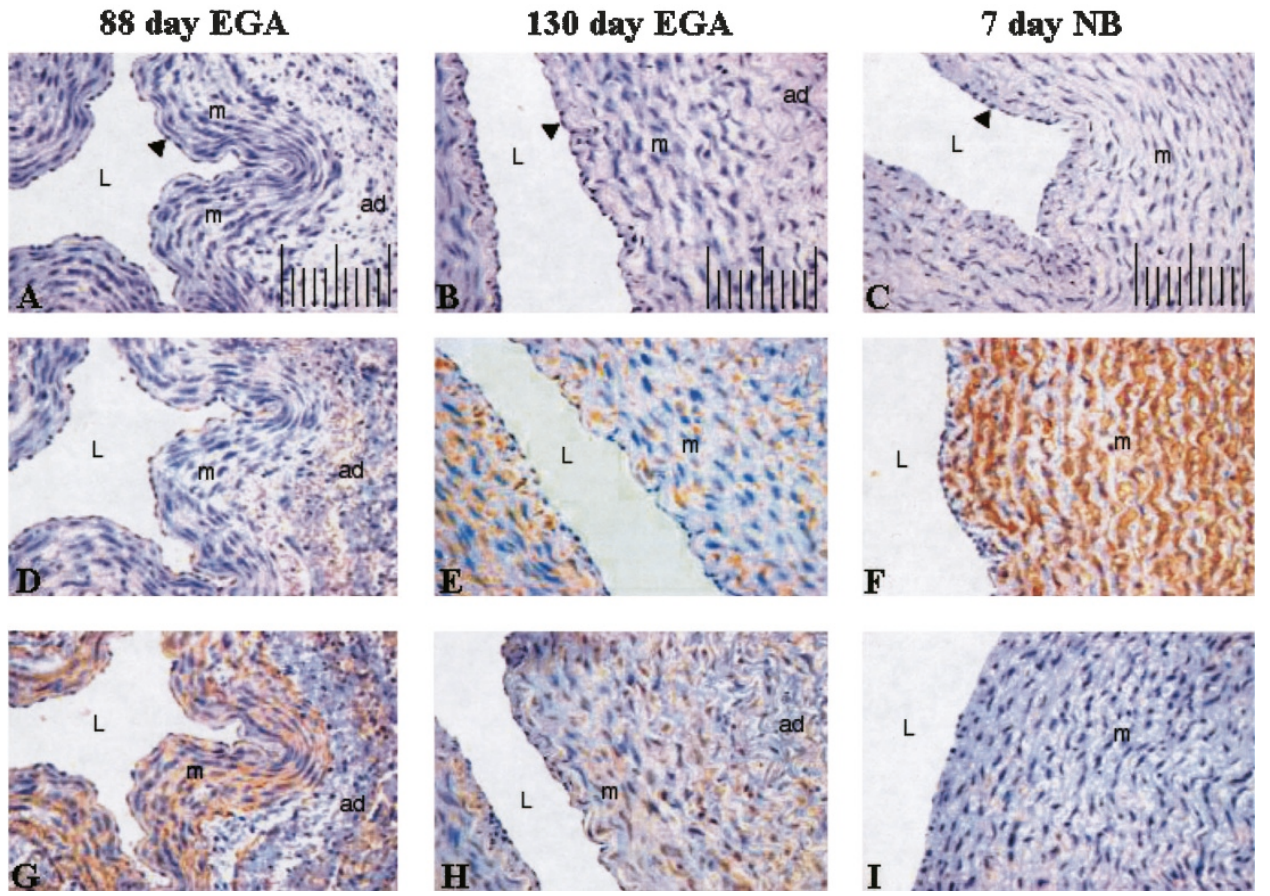

Figure 11. Representative immunohistochemistry of $\mathrm{AT}_{1}$ and $\mathrm{AT}_{2}$ expression in the carotid artery during ovine development. (A-C) Representative controls with nonimmune rabbit serum. $(D-F) \mathrm{AT}_{1}$. $(G-I) \mathrm{AT}_{2}$. Minimal $\mathrm{AT}_{1}$ immunostaining is observed in the medial smooth muscle at $88 \mathrm{~d}(D)$ compared with $130 \mathrm{~d}$ $(E)$ gestation and is restricted to the media. After birth, medial $\mathrm{AT}_{1}$ immunostaining is markedly increased compared with prenatal tissues $(F)$. In contrast, $\mathrm{AT}_{2}$ immunostaining is substantial at $88 \mathrm{~d}$ gestation $(G)$, decreases at $130 \mathrm{~d}(H)$, and is barely detectable at $7 \mathrm{~d}$ postnatal $(I)$. Immunostaining is not detected in the endothelium for either receptor at any age studied. The arterial lumen (L), media (m), and adventitia (ad), as well as endothelial cells ( $\mathbf{v})$, are identified. Magnification: $\times 40$.

inhibited systemic pressor responses to infused Ang II. We believe that this difference in AT subtype expression in umbilical and peripheral VSM represents an important mechanism for responses to stress- or hypoxic-induced increases in fetal Ang II. Because umbilical blood flow $\left(\sim 200 \mathrm{~mL} \cdot \min ^{-1}\right.$. $\mathrm{kg}^{-1}$ ) accounts for $40-50 \%$ of fetal cardiac output and a $50 \%$ decrease in blood flow does not alter fetal-placental $\mathrm{O}_{2}$ uptake or delivery (41), Ang II-induced vasoconstriction may redirect substantial quantities of oxygenated blood to tissues that express $\mathrm{AT}_{2}$, e.g. the cerebral vasculature (42), thereby maintaining tissue $\mathrm{O}_{2}$ delivery (5).

The carotid artery contributes to the regulation of fetal cerebral perfusion (31). Therefore, understanding its development and maturation is of considerable interest. The pattern of AT subtype expression in carotid VSM differs from the umbilical artery. Although $\mathrm{AT}_{1}$ mRNA was unchanged before birth, protein levels rose in the last $2 \mathrm{wk}$ of gestation and even further in the first postnatal month, paralleling increases in mRNA. This is best seen in the immunohistochemistry of the carotid artery and is consistent with data from Segar et al. (28) and radioligand binding $(19,20)$. However, $\mathrm{AT}_{2}$ mRNA and protein fell throughout development, resulting in decreased levels at term, after birth, and in the adult, again resembling data from radioligand binding $(19,20)$. Thus, compared with umbilical VSM, the switch from $\mathrm{AT}_{2}$ to $\mathrm{AT}_{1}$ occurs primarily after birth. Although the maturational changes in carotid VSM proteins are unknown, Segar et al. (28) observed Ang IImediated contraction responses in fetal carotid rings, albeit they were greatly attenuated compared with the adult. We have similar observations in denuded carotid rings (unpublished results) and are examining the maturational status of VSM protein. It is possible that the fall in $\mathrm{AT}_{2}$ expression permits Ang II-mediated responses by removal of attenuating mechanisms $(12,15,17)$.

The aorta of rats and mice have been extensively used to describe developmental changes in AT subtype expression but primarily as mRNA $(14,15,21,22)$. We therefore examined aortic VSM to determine whether the pattern of AT subtype mRNA resembled that in these species. Unlike umbilical and carotid VSM, aortic $\mathrm{AT}_{1}$ mRNA was unchanged throughout ovine development and resembled adult values. This is consistent with that reported in the developing rat and mouse $(14,21,22)$. The pattern of $\mathrm{AT}_{2}$ mRNA change also was similar, levels falling rapidly soon after birth $(14,21)$. Although aortic AT subtype mRNA is similar, the aorta is unlikely to contribute to fetal vascular responses to Ang II because aortic VSM from term fetal sheep has a diminished capacity to contract $(29,39)$, which is even more likely at even earlier stages of development.

The present study provides conclusive evidence that it is impossible to extrapolate the changes that occur in a single artery to the remainder of the developing vasculature $(29,43)$ because the pattern of AT subtype expression differed in each vessel studied. Similar differences occur in the maturational changes in smooth muscle proteins and the switch from a synthetic to a contractile phenotype $(29,32,39)$. We also observed that the regulation of AT subtype expression seems to differ between vessels. For example, whereas the rise in um- 
bilical $\mathrm{AT}_{1}$ protein parallels increases in mRNA and the fall in $\mathrm{AT}_{2}$ protein is unrelated to changes in mRNA levels, this differs from that observed in carotid VSM, where prenatal increases and decreases in carotid $\mathrm{AT}_{1}$ and $\mathrm{AT}_{2}$ protein, respectively, parallel changes in mRNA. A third mode of regulation is apparent in the abdominal aorta. Additional studies of AT subtype regulation are needed to address these differences and to determine which mechanisms govern vessel-specific differences in AT regulation. It is unlikely that changes in the hormonal milieu or levels of circulating Ang II and growth factors are involved, because exposure is likely to be similar, but this is not well studied. It also is unlikely to reflect AT subtype interactions (16). However, major differences exist between the carotid and umbilical artery, e.g. umbilical artery blood flow is substantially greater than cerebral perfusion and carotid artery $\mathrm{O}_{2}$ exposure exceeds that seen by the umbilical artery, reflecting fetal vascular shunts such as the ductus arteriosus. Neither explains why aortic VSM may differ. Alternatively, the mechanisms that regulate VSM maturation might contribute to AT subtype regulation (15). This, however, conflicts with observations in $\mathrm{AT}_{2}$ null mice suggesting that AT subtype expression regulates phenotypic changes in VSM proteins rather than the converse (22). In those studies, expression of aortic VSM calponin in $\mathrm{AT}_{2}$ null mice was delayed until after birth. Our studies in intact fetal sheep suggest that the developmentally regulated fall in $\mathrm{AT}_{2}$ receptors is associated with increases in VSM maturation and calponin rather than delays (unpublished results) $(29,39)$. Thus, $\mathrm{AT}_{2}$ null mice may develop alternative mechanisms for VSM maturation that differ from intact animals. The difference also may be species specific and requires further investigation.

GAPDH changes during development (35) and thus is not a useful reference gene in studies of the ovine fetal adrenal. We made similar observations for VSM MDH, but this was restricted to umbilical VSM. Thus, it is imperative to determine the ontogeny of each reference gene for each tissue of interest. We also observed that commercially available $\mathrm{AT}_{1}$ antisera detected three protein species, which probably represent differences in glycosylation of the $\sim 35-\mathrm{kD}$ native receptor $(12,44,45)$. The $\mathrm{AT}_{2}$ antisera detected only a $63-\mathrm{kD}$ protein, which we were able to deglycosylate to $35-41 \mathrm{kD}$ (data not shown), confirming previous reports $(12,44)$. It is believed that this modulates receptor trafficking. Irrespective of the $\mathrm{AT}_{1}$ antisera used, the pattern of protein expression in umbilical VSM was similar. We also noted that the $\mathrm{AT}_{1}$ antisera detected 3 -fold more protein in the soluble and total protein fractions compared with the plasma membrane in the umbilical artery and adult carotid. This has not previously been observed, and its significance is unclear because it was seen in both fetal and adult VSM.

In the present studies, we have characterized AT subtype expression in VSM from aorta and two arteries essential to fetal well-being and growth: the umbilical, which modulates fetoplacental blood flow, oxygenation, and nutrient supply, and the carotid, which contributes to the regulation of cerebral blood flow and oxygenation. Not only do the patterns of AT subtype expression differ but also their regulation. It is unclear what normally regulates AT transcription and translation dur- ing development and why this may differ between vessels. However, the present data now permit detailed studies of AT regulation and a comparison of subtype expression with phenotypic or maturational changes in VSM in this model, which may provide further insights into the role of the RAS in vascular development.

\section{REFERENCES}

1. Pipkin FB, Kirkpatrick SM, Lumbers ER, Mott JC 1974 Renin and angiotensin-like levels in foetal, new-born and adult sheep. J Physiol 241:575-588

2. Iwamoto HS, Rudolph AM 1981 Effects of angiotensin II on the blood flow and its distribution in fetal lambs. Circ Res 48:183-189

3. Lumber ER 1995 Functions of the renin-angiotensin system during development. Clin Exp Pharmacol Physiol 22:499-505

4. Schutz S, LeMoullec J-M, Corvol P, Gasc JM 1996 Early expression of all the components of the renin-angiotensin-system in human development. Am J Pathol 149:2067-2079

5. Iwamoto HS, Rudolph AM 1981 Role of renin-angiotensin system in response to hemorrhage in fetal sheep. Am J Physiol 240:H848-H854

6. Robillard JE, Gomez RA, Meernik JG, Kuehl WD, Van Orden D 1982 Role of angiotensin II on the adrenal and vascular responses to hemorrhage during development in fetal lambs. Circ Res 50:645-650

7. Scroop GC, Stankewytsch-Janush B, Marker JD 1992 Renin-angiotensin and autonomic mechanisms in cardiovascular homeostasis during haemorrhage in fetal and neonatal sheep. J Dev Physiol 18:25-33

8. Edwards LJ, Simonette G, Owens JA, Robinson JS, McMillen IC 1999 Restriction of placental and fetal growth in sheep alters fetal blood pressure responses to angiotensin II and captopril. J Physiol 515:897-904

9. Kaiser J, Cox BE, Roy TA, Rosenfeld CR 1998 Differential development of umbilical and systemic arteries. I. ANG II receptor subtype expression. Am J Physiol 274:R797-R807

10. Segar JL, Mazursky JE, Robillard JE 1994 Changes in ovine renal sympathetic nerve activity and baroreflex function at birth. Am J Physiol 267:H1824-H1832

11. Segar JL, Minnick A, Nuyt AM, Robillard JE 1997 Role of endogenous ANG II and $\mathrm{AT}_{1}$ receptors in regulating arterial baroreflex responses in newborn lambs. Am J Physiol 272:R1862-R1873

12. Gallinat S, Busche S, Raizada MK, Sumners C 2000 The angiotensin II type 2 receptor: an enigma with multiple variations. Am J Physiol 278:E357-E374

13. Berk BC 2003 Angiotensin type 2 receptor (AT2R): a challenging twin. Sci STKE PE16

14. Akishita M, Ito M, Lehtonen JY, Daviet L, Dzau VJ, Horiuchi M 1999 Expression of the AT2 receptor developmentally programs extracellular signal-regulated kinase activity and influences fetal vascular growth. J Clin Invest 103:63-71

15. de Gasparo M, Siragy HM 1999 The AT2 receptor: fact, fancy and fantasy. Regul Pept 81:11-24

16. Inagami T, Guo DF, Kitami Y 1994 Molecular biology of angiotensin II receptors: an overview. J Hypertens Suppl 12:S83-S94

17. Bottari S, de Gasparo M, Steckelings UM, Levens NR 1993 Angiotensin II receptor subtypes: characterization, signaling mechanisms, and possible physiologic implications. Front Neuroendocrinol 14:128-171

18. Rosenfeld CR, Cox BE, Magness RR, Shaul PW 1993 Ontogeny of angiotensin II vascular smooth muscle receptors in ovine fetal aorta and placental and uterine arteries. Am J Obstet Gynecol 168:1562-1569

19. Cox BE, Rosenfeld CR 1999 Ontogeny of vascular angiotensin II receptor subtype expression in ovine development. Pediatr Res 45:414-424

20. Burrell JH, Hegarty BD, McMullen JR, Lumbers ER 2001 Effects of gestation on ovine fetal and maternal angiotensin receptor subtypes in the heart and major blood vessels. Exp Physiol 86:71-82

21. Viswanathan M, Tsutsumi K, Correa FM, Saavedra JM 1991 Changes in expression of angiotensin receptor subtypes in the rat aorta during development. Biochem Biophys Res Commun 179:1361-1367

22. Yamada H, Akishita M, Ito M, Tamura K, Daviet L, Lehtonen JY, Dzau VJ, Horiuchi M $1999 \mathrm{AT}_{2}$ receptor and vascular smooth muscle differentiation in vascular development. Hypertension 33:1414-1419

23. Cox BE, Ipson MA, Shaul PW, Kamm KE, Rosenfeld CR 1993 Myometrial angiotensin II receptor subtypes change during ovine pregnancy. J Clin Invest 92:22402248

24. Cox BE, Word RA, Rosenfeld CR 1995 Angiotensin II receptor characterization and subtype expression in uterine arteries and myometrium during pregnancy. J Clin Endocrinol Metab 81:49-58

25. Cox BE, Rosenfeld CR, Kalinyak JE, Magness RR, Shaul PW 1996 Tissue specific expression of vascular smooth muscle angiotensin II receptor subtypes during ovine pregnancy. Am J Physiol 271:H212-H221

26. Shanmugam S, Corvol P, Gasc JM 1994 Ontogeny of the two angiotensin II type 1 receptor subtypes in rats. Am J Physiol 267:E828-E836

27. Shanmugam S, Lenkei ZG, Gasc JM, Corvol PL, Llorens-Cortes CM 1995 Ontogeny of angiotensin II type 2 (AT2) receptor mRNA in the rat. Kidney Int 47:1095-1100

28. Segar JL, Barna TJ, Acarregui MJ, Lamb FS 2001 Responses of fetal ovine systemic and umbilical arteries to angiotensin II. Pediatr Res 49:826-833

29. Arens Y, Chapados RA, Cox BE, Kamm KE, Rosenfeld CR 1998 Differential development of umbilical and systemic arteries. II. Contractile proteins. Am J Physio 274:R1815-R1823 
30. Rosenfeld CR, Gresores A, Roy TA, Magness RR 1995 Comparison of ANG II in fetal and pregnant sheep: metabolic clearance and vascular sensitivity. Am J Physio 268:E237-E247

31. Gratton R, Carmichael L, Homan J, Richardson B 1996 Carotid arterial blood flow in the ovine fetus as a continuous measure of cerebral blood flow. J Soc Gynecol Investig 3:60-65

32. Chern J, Kamm KE, Rosenfeld CR 1995 Smooth muscle myosin heavy chain isoforms are developmentally regulated in male and female neonatal sheep. Pediatr Res 38:697-703

33. Salhab WA, Shaul PW, Cox BE, Rosenfeld CR 2000 Regulation of types I and II NOS in ovine uterine arteries by daily and acute estrogen exposure. Am J Physio 278:H2134-H2142

34. Rosenfeld CR, Chen C, Roy T, Liu X 2003 Estrogen selectively up-regulates eNOS and nNOS in reproductive arteries by transcriptional mechanisms. J Soc Gynecol Investig 10:205-215

35. Wintour EM, Moritz K, Butkus A, Baird R, Albiston A, Tenis N 1999 Ontogeny and regulation of the $\mathrm{AT}_{1}$ and $\mathrm{AT}_{2}$ receptors in the ovine fetal adrenal gland. Mol Cel Endocrinol 157:161-170

36. Reagan LP, Theveniau M, Yang XD, Siemens IR, Yee DK, Reisine T, Fluharty S 1993 Development of polyclonal antibodies against angiotensin type 2 receptors. Proc Natl Acad Sci USA 90:7956-7960
37. Reagan LP, Sakai RR Fluharty SJ 1996 Immunological analysis of angiotensin AT receptors in peripheral tissues of neonatal and adult rats. Regul Pept 65:159-164

38. Owens GK 1995 Regulation of differentiation of vascular smooth muscle cells. Physiol Rev 75:487-517

39. Arens YH, Rosenfeld CR, Kamm KE 2000 Maturational differences between vascular and bladder smooth muscle during ovine development. Am J Physiol 278:R1305-R1313

40. Velaphi SC, Roy T, Despain K, Rosenfeld CR 2002 Differential responses to systemic and local angiotensin II infusions in conscious postnatal sheep. Pediatr Res 52:333-341

41. Wilkening RB, Meschia G 1983 Fetal oxygen uptake, oxygenation, and acid-base balance as a function of uterine blood flow. Am J Physiol 244:H749-H755

42. Tutsumi K, Saavedra JM 1991 Characterization of AT2 angiotensin II receptors in rat anterior cerebral arteries. Am J Physiol 261:H667-H670

43. Colbert MC, Kirby ML, Robbins J 1996 Endogenous retinoic acid signaling colocalizes with advanced expression of the adult smooth muscle myosin heavy chain isoform during development of the ductus arteriosus. Circ Res 78:790-798

44. Servant G, Dudley DT, Escher E, Guillemette G 1994 The marked disparity between the sizes of angiotensin type 2 receptors from different tissues is related to different degrees of $\mathrm{N}$-glycosylation. Mol Pharmacol 45:1112-1118

45. Lanctôt PM, Leclerc PC, Escher E, Leduc R, Guillemette G 1999 Role of Nglycosylation in the expression and functional properties of human $\mathrm{AT}_{1}$ receptor. Biochemistry 38:8621-8627 